\title{
BMJ
}

CHRISTMAS 2010: THE LIVES OF DOCTORS

\section{Phantom vibration syndrome among medical staff: a cross sectional survey}

\author{
Michael B Rothberg, clinician investigator Ashish Arora, critical care fellow Jodie Hermann, medical resident \\ Reva Kleppel, research assistant Peter St Marie, statistical intern Paul Visintainer, director of epidemiology \\ and biostatistics
}

\begin{abstract}
Division of General Medicine, Baystate Medical Center, Springfield, MA, and Tufts University School of Medicine Boston, MA, USA

Correspondence to: M B Rothberg, Division of General Medicine and Geriatrics, Baystate Medical Center, 759 Chestnut Street, Springfield, MA 01199, USA

Michael.Rothberg@bhs.org
\end{abstract}

Cite this as: BMJ 2010;341:C6914 doi:10.1136/bmj.c6914
ABSTRACT

Objective To describe the prevalence of and risk factors for experiencing "phantom vibrations," the sensory hallucination sometimes experienced by people carrying pagers or cell phones when the device is not vibrating. Design Cross sectional survey.

Setting Academic medical centre.

Participants 176 medical staff who responded to questionnaire ( $76 \%$ of the 232 people invited). Measurements Electronic survey consisting of 17 questions about demographics, device use, phantom vibrations experienced, and attempts to stop them. Results of the 169 participants who answered the question, 115 (68\%, 95\% confidence interval 61\% to $75 \%)$ reported having experienced phantom vibrations. Most (68/112) who experienced phantom vibrations did so after carrying the device between 1 month and 1 year, and $13 \%$ experienced them daily. Four factors were independently associated with phantom vibrations: occupation (resident $v$ attending physician, prevalence ratio $1.47,95 \%$ confidence interval 1.10 to 1.97 ), device location (breast pocket $v$ belt, prevalence ratio 1.66, 1.29 to 2.14 ), hours carried (per 6 hour increment, prevalence ratio $1.30,1.07$ to 1.58 ), and more frequent use in vibrate mode (per frequency category, prevalence ratio 1.18, 1.03 to 1.34$)$. Of those who experienced phantom vibrations, 43 (39\%, 30\% to $48 \%$ ) were able to stop them. Strategies for stopping phantom vibrations included taking the device off vibrate mode, changing the location of the device, and using a different device (success rates $75 \%$ v $63 \%$ v $50 \%$, respectively, $\mathrm{P}=0.217$ ). However, $39 \%$ ( $30 \%$ to $49 \%$ ) of respondents did not attempt any strategies.

Conclusions Phantom vibration syndrome is common among those who use electronic devices.

\section{INTRODUCTION}

Electronic devices, such as pagers and cell phones, have become ubiquitous in the information age. In order to maintain electronic access in quiet areas, users often place such devices on "vibrate" mode. Repeated use of the vibration mode may result in intermittent perception that the device is vibrating when, in fact, it is not. This sensation, sometimes referred to as phantom vibration syndrome, has been described in the lay press, ${ }^{1}$ but its prevalence has not been established. It is also not known what factors may increase the probability of experiencing phantom vibrations or which methods may be effective in dispelling them. We conducted a survey of medical professionals who are expected to carry an electronic communication device in order to assess the prevalence of this phenomenon and other factors associated with it.

\section{METHODS}

During May of 2010 we conducted a cross sectional survey of medical staff at Baystate Medical Center, an acute care hospital in western Massachusetts, and at an affiliated health centre. Our primary objective was to establish the prevalence of phantom vibrations among medical staff. Our secondary objective was to assess potential risk factors associated with experiencing phantom vibrations.

Because this was the first study of its kind (hypothesis generating), we did not perform a sample size calculation. Instead, all internal medicine physicians, medical students, and employees of the health centre (nurses, nurse practitioners, translators, and medical assistants) who were on the hospital paging system received an email invitation to participate in an anonymous online survey available through a link embedded in the email (Surveymonkey.com). To avoid biasing respondents, the invitation simply stated: "We are asking you to participate in a research study survey about electronic devices, such as beepers and cell phones, because in your job you carry a beeper." Members of the mailing list also received two follow-up reminders at roughly one week intervals. The survey was closed on 1 June 2010.

The web based survey, devised by us, contained 17 questions, including potential factors associated with phantom vibrations - age (in 10 year increments), sex, occupation, the type of device used, whether the 
Table 1 |Characteristics of the 176 respondents to survey of phantom vibration syndrome

\begin{tabular}{|c|c|c|c|}
\hline \multirow[b]{2}{*}{ Characteristic } & \multicolumn{2}{|c|}{ No (\%) of respondents } & \multirow[b]{2}{*}{$\begin{array}{l}\text { P value of } \\
\text { comparisont }\end{array}$} \\
\hline & $\begin{array}{c}\text { Total } \\
\text { (\% of column) }\end{array}$ & $\begin{array}{l}\text { With phantom vibrations } \\
\text { (\% of row })^{*}\end{array}$ & \\
\hline Age (years): & $169(100) \dagger$ & & \\
\hline $20-29$ & $56(33)$ & $45(80)$ & \multirow{5}{*}{$<0.001 \ddagger$} \\
\hline $30-39$ & $65(38)$ & $46(71)$ & \\
\hline $40-49$ & $30(18)$ & $18(60)$ & \\
\hline $50-59$ & $13(8)$ & $3(23)$ & \\
\hline $60-69$ & $5(3)$ & $3(60)$ & \\
\hline Sex: & $175(100)$ & & \\
\hline Men & $68(39)$ & $47 / 65(72)$ & \multirow{2}{*}{0.40} \\
\hline Women & $107(61)$ & 68/104 (65) & \\
\hline Occupation: & $163(100)$ & & \\
\hline Attending physician & $45(28)$ & $23(51)$ & \multirow{6}{*}{0.001} \\
\hline Resident physician & $67(41)$ & $52 / 65(80)$ & \\
\hline Medical student & $23(14)$ & 19/21 (90) & \\
\hline Nurse & $17(10)$ & $8(47)$ & \\
\hline Nurse practitioner & $4(2)$ & $3(75)$ & \\
\hline Medical assistant & $7(4)$ & $4(57)$ & \\
\hline Device carried: & $172(100)$ & & \\
\hline Pager & $148(86)$ & $99 / 145(68)$ & 0.99 \\
\hline Cell phone & $141(82)$ & $96 / 139(69)$ & 0.53 \\
\hline Device location: & $172(100)$ & & \\
\hline Belt & $68(40)$ & 46/66 (70) & \multirow{5}{*}{0.015} \\
\hline Side pocket & $73(42)$ & $52(71)$ & \\
\hline Breast pocket & $8(5)$ & $8(100)$ & \\
\hline Back pocket & $4(2)$ & $2(50)$ & \\
\hline Other & 19 (11) & $7 / 18$ (39) & \\
\hline Use device in vibrate mode: & $172(100)$ & & \\
\hline Never & $19(11)$ & $6 / 17(35)$ & \multirow{4}{*}{$<0.001 \ddagger$} \\
\hline Intermittently & $55(32)$ & $28(51)$ & \\
\hline Most of the time & $52(30)$ & $45(87)$ & \\
\hline Always & $46(27)$ & $36 / 45(80)$ & \\
\hline Hours per day: & $169(100)$ & & \\
\hline$<6$ & $3(2)$ & 0 & \multirow{3}{*}{$0.004 \ddagger$} \\
\hline $6-12$ & $106(63)$ & $66 / 105(63)$ & \\
\hline$>12$ & $60(36)$ & $48(80)$ & \\
\hline Mean No of pages per hour: & $168(100)$ & & \\
\hline$<5$ & $93(55)$ & $59 / 92(64)$ & \multirow{4}{*}{$0.16 \ddagger$} \\
\hline $5-10$ & $63(38)$ & $45(71)$ & \\
\hline $11-15$ & $6(4)$ & $5(83)$ & \\
\hline$>15$ & $6(4)$ & $5(83)$ & \\
\hline Maximum No of pages per hour: & $169(100)$ & & \\
\hline$<5$ & $47(28)$ & $28(60)$ & \multirow{4}{*}{$0.32 \ddagger$} \\
\hline $5-10$ & $45(27)$ & $32(71)$ & \\
\hline $11-15$ & $35(21)$ & $26(74)$ & \\
\hline$>15$ & $42(25)$ & 28/41 (68) & \\
\hline
\end{tabular}

${ }^{\star}$ Numbers adjusted for those who did not answer both the question about phantom vibrations and about the particular characteristic.

tComparisons made with Fisher's exact test unless stated otherwise.

$\ddagger$ Non-parametric test for trend. to stop the vibrations, and whether any of these were successful. The survey was pilot tested to assure clarity and coherence, and it was subsequently modified in response to the pilot results. The study was approved by the institutional review board of Baystate Medical Center.

\section{Statistical analysis}

We conducted comparisons between the primary outcome (presence or absence of phantom vibrations) and categorical variables using Fisher's exact test and Cuzick's non-parametric test for trends, ${ }^{2}$ since all data were coded in either nominal or ordered categories. Major prevalence estimates are reported with 95\% confidence intervals. Since the survey responses reflect prevalence data, our multivariable analyses used Poisson regression with robust standard errors in order to facilitate interpretation of the prevalence ratios and to produce valid estimates of the confidence intervals for prevalence ratios. ${ }^{3}$

For the variables that were categorical, the prevalence ratios reflect the ratio of the proportion of those with the characteristic who have a positive response to the proportion of those without the characteristic who have a positive response, adjusting for other covariates in the model. For variables that were ordinal (such as number of hours that the device was carried), the prevalence ratios reflect an increase in the estimated prevalence of phantom vibrations for each level increase in the ordinal variable (such as from $<6$ hours to $6-12$ hours), adjusting for other model covariates. Given the limited sample size for age and occupation categories, interactions among these characteristics were not explored.

For univariable analyses, observations with missing data for specific variables were excluded from analyses using those variables (that is, casewise deletion). Multivariable models were based on observations with valid values for all variables included in the final model (that is, listwise deletion) Associations from univariable and multivariable analyses were considered significant at a critical test level of 5\%; prevalence ratio estimates are reported along with 95\% confidence intervals. All analyses were conducted in Stata (version 11.1, StataCorp, College Station, TX).

\section{RESULTS}

Of the 232 people who received the email invitations, $176(76 \%)$ responded, and table 1 lists their characteristics. In all, 115/169 (68\%, 95\% confidence interval $61 \%$ to $75 \%$ ) reported having experienced phantom vibrations. Phantom vibrations were equally common with pagers and cell phones (99/145 (68\%) v 96/139 (69\%), $\mathrm{P}=0.80)$. Most respondents began experiencing phantom vibrations after carrying the device for between one month and one year (68/112 (61\%, 51\% to $70 \%)$ ), but $18(16 \%)$ experienced them after less than a month, and 26 (23\%) did not experience them until they had used the device for a year or more (table 2). Most respondents experienced the phantom vibrations either and how frequently it rang - and whether the respondent had experienced phantom vibrations (survey available on request). For those who reported phantom vibrations, we also asked how often they occurred, how bothersome they were, what methods users employed 
Table 2 Characteristics of phantom vibrations experienced by 115 respondents to survey of phantom vibration syndrome

\begin{tabular}{|c|c|}
\hline Characteristic & $\begin{array}{l}\text { No }(\%) \text { of } \\
\text { respondents* }\end{array}$ \\
\hline Ever experienced phantom vibrations & 115 \\
\hline \multicolumn{2}{|l|}{ Bothersomeness: } \\
\hline Not at all & $37 / 114(32)$ \\
\hline A little & 69/114 (61) \\
\hline Bothersome & $6 / 114(5)$ \\
\hline Very bothersome & $2 / 114$ (2) \\
\hline \multicolumn{2}{|l|}{ Duration of use of device before phantom vibrations began: } \\
\hline «1 month & 18/112(16) \\
\hline $1-5$ months & 46/112 (41) \\
\hline $6-12$ months & $22 / 112(20)$ \\
\hline$>12$ months & 26/112(23) \\
\hline \multicolumn{2}{|l|}{ Frequency of phantom vibrations: } \\
\hline Daily & 14/111 (13) \\
\hline Weekly & 43/111 (39) \\
\hline Monthly & 54/111 (49) \\
\hline Succeeded in stopping the phantom vibrations & 43/111 (39) \\
\hline \multicolumn{2}{|l|}{ Moving the device } \\
\hline Helpful & 29/105 (28) \\
\hline Not helpful & $17 / 105(16)$ \\
\hline Not attempted & $59 / 105(56)$ \\
\hline \multicolumn{2}{|l|}{ Stop using in vibrate mode } \\
\hline Helpful & 27/103 (26) \\
\hline Not helpful & 9/103 (9) \\
\hline Not attempted & 67/103 (65) \\
\hline \multicolumn{2}{|l|}{ Change device } \\
\hline Helpful & 7/99 (7) \\
\hline Not helpful & $7 / 99(7)$ \\
\hline Not attempted & 85/99 (86) \\
\hline
\end{tabular}

weekly or monthly $(97 / 111(87 \%, 80 \%$ to $93 \%))$, but 14 $(13 \%, 7 \%$ to $20 \%)$ experienced them on a daily basis.

\section{Secondary analyses}

In univariate analysis, five factors were associated (defined as $\mathrm{P}<0.05$ ) with experiencing phantom vibrations: age, occupation, device location, hours worn per day, and how often the device was used in vibrate mode. In multivariable analysis, only occupation (or age), device location, and how often the device was in vibrate mode remained significantly associated with phantom vibrations (table 3). Because age and occupation were highly co-linear in this sample, it was impossible to estimate their effects on phantom vibrations simultaneously. Both variables had a similar influence on the other variables when modelled separately.

Most respondents who experienced phantom vibrations found the sensation to be not at all or only a little bothersome (106/114 (93\%, 87\% to $97 \%))$. However, $8 / 114$ respondents $(7 \%, 2 \%$ to $12 \%)$ found the sensation to be bothersome or very bothersome. Finally, of those who experienced phantom vibrations, 43/110 (39\%, 30\% to $48 \%)$ were able to stop them. Strategies for stopping them included taking the device off vibrate mode, changing the location of the device, and using a different device (success rates of 27/36 $(75 \%)$ v 29/46 (63\%) v 7/14 (50\%), respectively, $\mathrm{P}=0.217)$. Interestingly, $42 / 108(39 \%, 30 \%$ to $49 \%)$ respondents did not attempt any strategies to stop the phantom vibrations.

\section{DISCUSSION}

In this cross sectional survey of medical staff, we found that almost $70 \%$ had experienced phantom vibrations from an electronic device. The perceptions were most common among students and house staff and were associated with frequency of use. Most respondents found the sensations to be only mildly annoying, but $2 \%$ found them very bothersome. As a result, only $61 \%$ had tried to stop them, and most of those who tried succeeded in extinguishing the sensation-either by moving the device or refraining from using it in vibrate mode.

\section{Comparison with other studies}

This is the first report of this phenomenon that we are aware of in the medical literature. In a graduate thesis published in 2007 on "Emotional and behavioral aspects of mobile phone use," David Laramie surveyed 320 adult mobile phone users and found that two thirds had experienced phantom rings, ${ }^{4}$ similar to the proportion we report. The study was reported in the popular press, and the condition is discussed on numerous blogs and eHealth sites. There are at least three phantom vibration syndrome groups on Facebook.

Just as the Holy Roman Empire was not holy, Roman, or an empire, phantom vibration syndrome does not involve a phantom, nor is it technically a syndrome. The sensations are better characterised as tactile hallucinations, in which the brain perceives a sensation that is not actually present. Because the word hallucination carries a connotation of mental illness, whereas the phantom vibration syndrome

Table $3 \mid$ Multivariable model of predictors for experiencing phantom vibration syndrome

\begin{tabular}{lll} 
Characteristic & $\begin{array}{c}\text { Prevalence ratio } \\
(95 \% \mathrm{Cl})\end{array}$ & P value \\
$\begin{array}{l}\text { Hours that device is carried } \\
\text { (per } 6 \text { hour increment) }\end{array}$ & $1.30(1.07$ to 1.58$)$ & 0.008 \\
\hline $\begin{array}{l}\text { Use of device in vibrate mode } \\
\text { (per frequency category) }\end{array}$ & $1.18(1.03$ to 1.34$)$ & 0.016 \\
\hline Occupation of respondent: & 1.00 (reference) & \\
\hline Attending physician & $1.47(1.10$ to 1.97$)$ & 0.010 \\
\hline Resident physician & $1.46(1.05$ to 2.01$)$ & 0.022 \\
\hline Medical student & $1.15(0.77$ to 1.73$)$ & 0.49 \\
\hline Other clinician or technician & \multicolumn{1}{l}{} \\
\hline Device location: & $1.00($ reference $)$ & \\
\hline Belt & $1.10(0.89$ to 1.36$)$ & 0.36 \\
\hline Side pocket & $1.66(1.29$ to 2.14$)$ & $<0.001$ \\
\hline Breast pocket & $0.79(0.31$ to 2.00$)$ & 0.62 \\
\hline Back pocket & $0.69(0.35$ to 1.40$)$ & 0.31 \\
\hline Other & & \\
\hline
\end{tabular}

Total number for the analysis is 158 


\section{WHAT IS ALREADY KNOWN ON THIS TOPIC}

Phantom vibrations-the sensation that an electronic device is vibrating when it is not-have been reported in the lay press

The prevalence and risk factors for phantom vibrations have not been studied

\section{WHAT THIS STUDY ADDS}

The prevalence of phantom vibrations in a population of medical staff was nearly $70 \%$

The perceptions were most common among students and house staff and were associated with frequency of use and carrying the device in a breast pocket

However, only $2 \%$ of those affected found the vibrations very bothersome

appears to occur in a majority of normal individuals, and because so many are already using the term, it seems appropriate to let the popular appellation stand.

The cause of phantom vibration syndrome has not been explored but may result from a misinterpretation of incoming sensory signals by the cerebral cortex. In order to deal with the overwhelming amount of sensory input, the brain applies filters or schema based on what it expects to find, a process known as hypothesis guided search. ${ }^{5}$ In the case of phantom vibrations, because the brain is anticipating a call, it misinterprets sensory input according to this preconceived hypothesis. The actual stimulus is unknown, but candidate sensations might include pressure from clothing, muscle contractions, or other sensory stimuli.

Although hallucinations are sometimes pathological, they often occur in normal individuals and are not limited to vibrations. Auditory hallucinations of cell phone ring tones also occur. ${ }^{6}$ The extremely high prevalence of phantom vibrations encountered in our sample attests to the fact that normal brain mechanisms are at work. Why some individuals experience it while others do not, why it is more common in younger people (or house staff), and why some body locations seem to be more prone than others to developing phantom vibrations remain unanswered questions. It may be that neural plasticity of younger people makes them more susceptible to imagine vibrations. Alternatively, it may be that pages received by medical students and house staff are more likely to require urgent attention than those received by attending physicians. Like new mothers who constantly imagine they hear their baby crying, students and residents check and recheck their pagers.

For those who attempted to stop the phantom vibrations, relocating the device was often successful. Possibly, moving the source of the vibrations interferes with the brain's creation of a sensory memory for that particular location. Also the sensations, which were associated with frequency of use, seemed to disappear if not reinforced. Refraining from using the device in vibrate mode did not work for everyone, however, and some people felt the device vibrating even when they were not in contact with it.

\section{Strengths and limitations of the study}

Our study had several limitations. Firstly, it was a survey limited to medical professionals in a single institution. It is not known whether others would experience the same prevalence of phantom vibrations. However, our findings are similar to those reported in a graduate thesis studying the general population. Secondly, frequency of use was self reported. Subjects may have overestimated or underestimated their exposures. Similarly, efforts to stop the vibrations were also assessed retrospectively without controls. More study is required to understand what causes phantom vibrations and how to make them stop. Thirdly, although our response rate was high, $24 \%$ of those invited to participate declined to do so. We tried to hide the exact nature of the survey, but those who took it early may have revealed the content to others and thereby introduced a bias into our sample. Finally, our survey represents a single point in time. Prospective studies may better predict who will develop phantom vibration syndrome and define its long term prognosis.

\section{Conclusions and implications}

More than half the people on the planet now carry some sort of cellular phone, ${ }^{7}$ and many of these will set the device on vibrate mode at least some of the time. If two thirds of these people develop phantom vibrations - even if they are not very bothersomethen the global impact is substantial. If even a small proportion of users experience severe symptoms, then effective treatment will be required. More research is needed to understand why phantom vibration syndrome occurs and how to stop it. Once the aetiology of phantom vibration syndrome is identified, users can take steps to avoid it, or at least to ameliorate the symptoms.

The study was conducted with the goodwill of the participants and investigators.

Funding: None

Competing interests: All authors have completed the Unified Competing Interest form at www.icmje.org/coi_disclosure.pdf (available on request from the corresponding author) and declare: no support from any organisation for the submitted work; no financial relationships with any organisations that might have an interest in the submitted work in the previous three years, no other relationships or activities that could appear to have influenced the submitted work

Ethical approval: Consent was not obtained but the presented data are anonymised and risk of identification is low.

Data sharing: Complete survey and dataset available from MBR at Michael.Rothberg@bhs.org.

1 Haupt A. Good vibrations? Bad? None at all? USA Today 2007 June 12, 2007.

2 Cuzick J. A Wilcoxon-type test for trend. Stat Med 1985;4:87-90.

3 Barros AJ, Hirakata VN. Alternatives for logistic regression in crosssectional studies: an empirical comparison of models that directly estimate the prevalence ratio. BMC Med Res Methodol 2003;3:21.

4 Laramie D. Emotional and behavioral aspects of mobile phone use [PhD thesis]. Alliant International University, 2007.

5 Pennebaker JW, Skelton JA. Selective monitoring of physical sensations. J Pers Soc Psychol 1981;41:213-23.

6 Goodman B. I hear ringing and there's no one there. I wonder why. New York Times 2006 May 4.

7 Market Information and Statistics Division TDB, International Telecommunication Union. The world in 2009: ICT facts and figures. International Telecommunications Union, 2009.

Accepted: 24 November 2010 